\title{
Rational Drug Repurposing: Focus on Lysosomotropism, Targets in Disease Process, Drug Profile, and Pulmonary Tissue Accumulation in SARS-CoV-2 Infection/COVID-19
}

\begin{abstract}
Markus Blaess ${ }^{1}$, Lars Kaiser ${ }^{1,2}$, Oliver Sommerfeld ${ }^{3}$, Simone Rentschler ${ }^{1}$, René Csuk ${ }^{4}$ and Hans-Peter Deigner ${ }^{1,5,6 *}$

'Institute of Precision Medicine, Medical and Life Sciences Faculty, Furtwangen University, Villingen-Schwenningen, Germany, ${ }^{2}$ Institute of Pharmaceutical Sciences, University of Freiburg, Freiburg, Germany, ${ }^{3}$ Department of Anaesthesiology and Intensive Care Medicine, Jena University Hospital, Jena, Germany, ${ }^{4}$ Department of Organic Chemistry, Martin-Luther-University HalleWittenberg, Halle (Saale), Germany, ${ }^{5}$ EXIM Department, Fraunhofer Institute IZI Leipzig, Rostock, Germany, ${ }^{6}$ Faculty of Science, Tuebingen University, Tübingen, Germany
\end{abstract}

Keywords: SARS-CoV-2, COVID-19, lysosomotropic compounds, approved active compounds, cytokine storm syndrome, lysosomotropism, repurposing approved drugs, lysosome

\section{INTRODUCTION}

Edited by: Rafael Maldonado,

Pompeu Fabra University, Spain

Reviewed by:

Nadezhda A. German,

Texas Tech University Health Sciences

Center, United States

*Correspondence:

Hans-Peter Deigner

Hans-Peter.Deigner@hs-furtwangen.de

Specialty section:

This article was submitted to Experimental Pharmacology and

Drug Discovery,

a section of the journal

Frontiers in Pharmacology

Received: 18 July 2020 Accepted: 06 October 2020 Published: 20 November 2020

Citation:

Blaess M, Kaiser L, Sommerfeld O, Rentschler S, Csuk R, Deigner H-P (2020) Rational Drug Repurposing: Focus on Lysosomotropism, Targets in Disease Process, Drug Profile, and

Pulmonary Tissue Accumulation in SARS-CoV-2 Infection/COVID-19.

Front. Pharmacol. 11:584881.

doi: 10.3389/fphar.2020.584881
The pandemic severe acute respiratory syndrome coronavirus 2 (SARS-CoV-2) has been identified as the disease-causing pathogen of Coronavirus disease 2019 (COVID-19). (Pre) clinical research to identify rapidly available small molecules for the treatment of SARS-CoV-2 infections/COVID-19 has focused to date on the approved lysosomotropic antimalarials chloroquine and hydroxychloroquine, the investigational remdesivir (GS-5734, compassionate use), and the anti-inflammatory corticosteroid dexamethasone (COVID-19 Treatment Guidelines Panel, 2020). Lopinavir/ritonavir and other HIV protease inhibitors, however, were discontinued as treatment options in COVID-19 demonstrating no clinical benefit in clinical trials.

Despite encouraging results in treating hospitalized patients with COVID-19 requiring supplemental oxygen, mechanical ventilation, or extracorporeal membrane oxygenation (ECMO) with remdesivir and dexamethasone, there is still a lack of active compounds exhibiting pancoronavirus antiviral activity, tackling or preventing host cell infection, forming syncytia, endotheliitis, or the cytokine release syndrome (CRS)/cytokine storm syndrome in COVID-19. Target-oriented and in particular site of action-oriented drug repurposing of small molecules has the potential to close the gap in prophylaxis and treatment of mild and moderate COVID-19 and to reduce mortality in severe cases.

\section{OXIDATIVE STRESS, APOPTOSIS, MULTINUCLEATE SYNCYTIA, HOST CELL ENTRY, AND CYTOKINE STORM SYNDROME DEFINE DRUG REPURPOSING TARGETS}

Oxidative stress (e.g., enhanced ROS levels) has been demonstrated in animal models of SARS (Delgado-Roche and Mesta, 2020) and serves as a possible explanation why SARS-CoV-2 patients with Glucose-6-phosphate dehydrogenase (G6PD) deficiency develop intravascular hemolysis and methemoglobinemia (Palmer et al., 2020). Both, chloroquine and hydroxychloroquine, are supposed to 


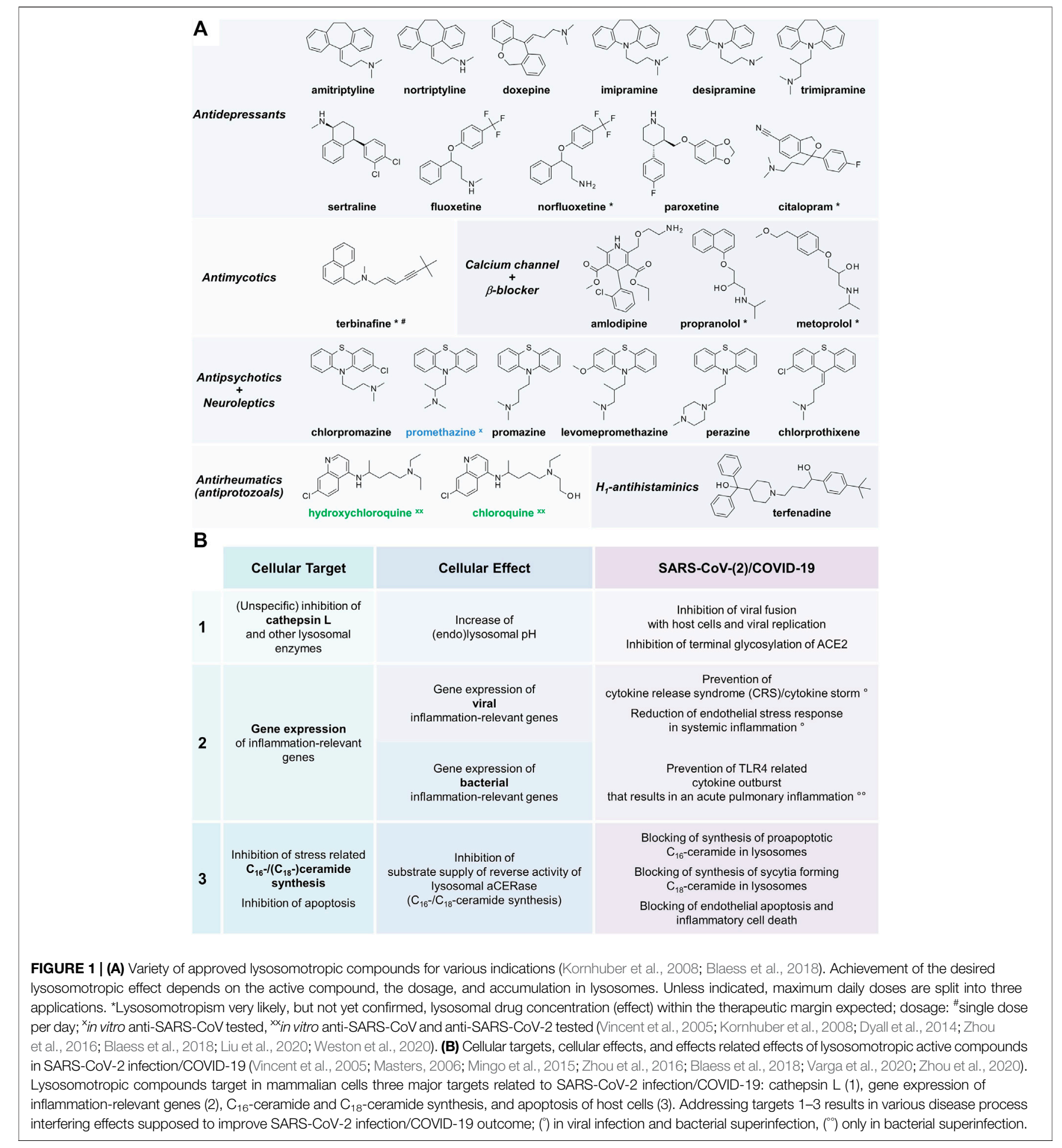

trigger severe drug-induced hemolytic anemia in G6PD-deficient COVID-19 patients (Beauverd et al., 2020; Kuipers et al., 2020).

Severe COVID-19 is associated with an atypical diffuse alveolar damage, ending in the acute respiratory distress syndrome (ARDS) (Huang et al., 2020), most likely accompanied by occurrence of syncytia as a result of a direct infection of cells by an infected neighboring cell without releasing a complete virus (Ou et al., 2020).

Ceramides, in particular $\mathrm{C}_{18}$-ceramide, are present in (sepsisinduced) cardiac dysfunction (Chung et al., 2017), and are effective in triggering exocytosis in rat PC12 cells (Tang et al., 2007); further they may contribute to SARS-CoV-2-related 
cell-cell fusion by exocytosis of viral $\mathrm{S}$ protein fractions and development of multinucleate syncytia.

Non-structural protein nsp2 of SARS-CoV-2 was associated with host cell cell cycle progression, and apoptosis in host cells, suggesting an impact on disrupting the host cell environment (Yoshimoto, 2020) and apoptosis of endothelial cells (Varga et al., 2020).

According to current knowledge, cleavage-mediated fusion of viral $S$ protein with host cells can occur either immediately at the cell surface by TMPRSS2 or within the lysosome catalyzed by lysosomal cathepsin L (Belouzard et al., 2012). The lysosomal cathepsin L induced fusion of SARS particles bound to ACE2 with host cells (Millet and Whittaker, 2015) is sensitive to lysosomal pH. Hence both, TMPRSS2 and cathepsin L, display promising targets of prophylaxis and treatment of SARS-CoV-2 infection/ COVID-19.

In severe COVID-19, SARS-CoV-2 is likely to cause both, pulmonary and systemic inflammation, thus leading to multiorgan dysfunction in high risk populations. Significantly higher concentrations of IL-8, TNFa, and IL-6 in deceased patients (Chen et al., 2020) are suggesting a rapid and severe deterioration during SARS-CoV-2 infection associated with CRS/cytokine storm syndrome (Mehta et al., 2020).

\section{LYSOSOMOTROPIC (ACTIVE) COMPOUNDS ARE VALUABLE DRUG CANDIDATES}

Lysosomotropism is a biological characteristic of small molecules and always present in addition to intrinsic pharmacological effects. Various well-known approved drugs such as amitriptyline, chlorpromazine, sertraline, and imipramine share lysosomotropic characteristics (Figure 1A) (Kornhuber et al., 2008; Blaess et al., 2018). Regardless of their pharmacological effects, they are accumulating in lysosomes raising the lysosomal $\mathrm{pH}$ from $4.5-5$ to $6-6.5$, beyond the optimum of most of the lysosomal enzymes, including cathepsin L. Since no effects of lysosomotropic aminoglycoside antibiotics on free cathepsin L (Zhou et al., 2016) or other lysosomotropic drugs on lysosomal enzymes such as acid sphingomyelinase exist (Blaess et al., 2018), a selective inhibition is unlikely.

Lysosomotropic compounds are not limited to mediate inactivation of cathepsin L Figure 1B. Moreover, lysosomotropic compounds are assumed to suppress the CRS/ cytokine storm syndrome and to attenuate the transition from mild to severe SARS-CoV-2 infection/COVID-19 (Zhou et al., 2020). Data of the lysosomotropic model compound NB 06 in LPS-induced inflammation in monocytic cells (Blaess et al., 2018) supports the hypothesis. NB 06 affects gene expression of the prominent inflammatory messengers IL1B, IL23A, CCL4, CCL20, and IL6; likewise, it has beneficial effects in (systemic) infections involving bacterial endotoxins by targeting the TLR4 receptor pathway in sepsis. Similarly, desipramine reduces endothelial stress response in systemic inflammation (Chung et al., 2017).

Apoptosis of (infected) mammalian cells is characterized by an increase in $\mathrm{C}_{16}$-ceramide (Thomas et al., 1999) and can be blocked via lysosomotropic compounds such as NB 06, chlorpromazine, and imipramine (Blaess et al., 2018). Furthermore, $\mathrm{C}_{18}$-ceramide triggered exocytosis and forming of syncytia is blocked by chlorpromazine as well (Garner et al., 2010).

\section{SUITABLE DRUG PROFILES AND ROUTES OF ADMINISTRATION}

According to current knowledge, in therapy inhibition of lysosomal pH dependent processes (e.g., cathepsin L dependent viral entry into host cells) can be obtained only through off-label use of lysosomotropic drugs. Systemic application in lysosomotropic drug concentrations and obtaining an efficacious blood level is sometimes accompanied by severe adverse effects and/or (in this case) undesirable (intrinsic) pharmacological effects. Chloroquine was among the first lysosomotropic active compounds exerting antiviral effects on SARS-CoV-2 (Liu et al., 2020) and during SARS-CoV pre- and post-infection conditions (Vincent et al., 2005). Owing to an unfavorable drug profile (G6PD patients, insufficient lysosomotropism, elimination half-life of $45 \pm$ 15 days), a recommendation against (hydroxy)chloroquine, but not against lysosomotropic active compounds in principle was issued (COVID-19 Treatment Guidelines Panel, 2020).

Chlorpromazine displayed anti-SARS-CoV-2 effects in vitro (Weston et al., 2020) and protective effects on COVID-19 in patients in a psychiatry hospital (NCT04366739). Consequently, chlorpromazine is rated as a promising candidate in COVID-19/ CRS treatment. In case of treatment of people without mental illness, however, a premature termination of treatment due to severe side effects by systemic application of chlorpromazine is extremely likely. This raises the question of how to handle this issue to provide well tolerated lysosomotropic drugs in SARSCoV-2 infection/COVID-19.

\section{PERSONALIZED BENCH TO BEDSIDE TREATMENT CONCEPT}

Numerous available approved drugs with lysosomotropic characteristics permit tailor-made therapy. The individual preexisting conditions are a criterion for the selection and combination of lysosomotropic drugs. For choosing suitable lysosomotropic drugs some issues have to be considered:

\section{Tolerable Intrinsic Pharmacology and Drug Profile}

Various lysosmotropic drugs in Figure 1A demonstrated antiSARS-CoV(-2) efficacy (Dyall et al., 2014; Zhou et al., 2016; Liu et al., 2020; Weston et al., 2020), offer a more favorable drug profile than the initially investigated chloroquine and hydroxychloroquine. 


\section{Accumulation In Lysosomes of Pulmonary Tissue}

Imipramine and chlorpromazine are accumulating in isolated perfused lung tissue and imipramine in alveolar macrophages (Wilson et al., 1982; Macintyre and Cutler, 1988) suggesting that lysosomotropic drug concentrations in pulmonary alveoli and protective effects on SARS-CoV-2 infection of particular drugs are likely. Of the lysosomotropic in vitro anti-SARS-CoV-2 antibiotics teicoplanin, oritavancin, dalbavancin, and telavancin (Zhou et al., 2016), solely teicoplanin and telavancin are in accumulating pulmonary tissue and are expected to be a treatment option.

\section{Additional Therapeutic Benefits In Sars-Cov-2 Infection/Covid-19}

Beside lysosomotropism certain intrinsic pharmacological effects are advantageously in SARS-CoV-2 infection/COVID-19. The incidence of CRS/cytokine storm syndrome associated with secondary gram-positive bacterial infections is likely to be minimized by using the pulmonary tissue accumulating antibacterials teicoplanin and telavancin or the antifungal itraconazole in systemic mycoses in appropriate systemic drug levels.

\section{Choosing A Suitable Route of Administration}

Systemic application of chlorpromazine (NCT04366739) and fluoxetine (NCT04377308) as lysosomotropic drugs may provoke severe and unfavorable adverse effects in mental healthy patients. Since the respiratory tract is both, the gateway for SARS-CoV-2 infection/COVID-19 and an internal surface, the expedient is a local application in the airways and/or the respiratory tract. Local application of small molecules is possible, preferably as inhalant or via nebulizers to avoid (undesirable) systemic effects. The majority of lysosomotropic drugs should be suitable for inhalation.

\section{Combination With Antivirals and Tmprss2 Inhibitors}

COVID-19 originates from a SARS-CoV-2 infection that could not be tackled successfully by the immune system. The antiviral remdesivir proved to be effective in infection prophylaxis (phase 0) (de Wit et al., 2020) and viral (SARS-CoV-2) infection (phase 1) within a limited period (5-6 days), shortly after the symptoms emerge and viral shedding occurs (Mitjà and Clotet, 2020). In severe COVID-19 neither a lower mortality nor a faster clearance of viruses was observed (Wang et al., 2020). As soon as the infection initiates a CRS/ cytokine storm, it is likely that the transition toward COVID-19 (phase 2), a disseminated intravascular coagulation/thrombotic microangiopathy, or a bacterial secondary infection occurs. An effective multi-drug therapy, focusing on the progression of
COVID-19 and emerging severe complications, can be implemented by lysosomotropic drugs, TMPRSS2 inhibitors and antivirals.

\section{NAFAMOSTAT: AN IN VIVO TMPRSS2 INHIBITOR?}

Nafamostat is an approved protease inhibitor that inhibits TMPRSS2 (in vitro) (Hoffmann et al., 2020), prevents (sepsis-related) disseminated intravascular coagulation, and thrombotic microangiopathy (Okajima et al., 1995; Levi and Thachil, 2020), appears to be useful in SARS-CoV-2 infection and prophylaxis, and for patients subjected to extracorporeal circulation such as ECMO (Han et al., 2011). It is doubtful, however, whether the pulmonary concentration in therapeutically dosage (Ono Pharmaceuticals, 2020) is sufficient to generate a TMPRSS2 inhibition in vivo as demonstrated in vitro due to poor accumulation in pulmonary tissue (Midgley et al., 1994).

\section{SINGLE OR MULTI TARGET APPROACH: LYSOSOMOTROPIC DRUGS VS. ANTIBODIES}

Various clinical trials are currently under way using immunomodulatory IL-1 and IL-6 inhibitors or anti-IL-6R antibodies (anakinra, tocilizumab, siltuximab, and sarilumab) in patients with COVID-19 (COVID-19 Treatment Guidelines Panel, 2020); limited data, however, is yet available. In a retrospective study using tocilizumab and hydroxychloroquine, both demonstrated a limited benefit in survival (Ip et al., 2020). Tocilizumab shortens mechanical ventilation and hospital stay in severe COVID-19 (Eimer et al., 2020), while tocilizumab is often accompanied by bacterial pneumonia 2 days after application (23\%) (Pettit et al., 2020).

To improve outcome, antibody cocktails consisting of antiIL-6, IL-1 receptor blocker, IL-1 type 1 receptor, and TNF- $\alpha$ are suggested (Harrison, 2020), irrespective of the risk of serious adverse effects (e.g., bacterial pneumonia) due to more pronounced interference with the immune defense. Such cocktails are intended to tackle the release of proinflammatory cytokines IL- $1 \beta$ and IL- 6 mediating lung and tissue inflammation, fever, and fibrosis, as they are supposed to be responsible for the emergence of COVID-19.

Although lysosomotropic drugs likewise interfere with the immune defense, such adverse effects are not reported. In contrast to antibodies, however, only the resynthesis of IL-6 and thus the available amount is reduced, but not completely obstructed, still allowing a moderate immune response. Multitargeting on core processes of the viral infection addressing the formation of multinucleate syncytia and alteration of tissue structure, ceramide metabolism, and the release of virions could be a key advantage of lysosomotropic drugs compared to current strategies. 


\section{FUTURE DIRECTIONS}

Daunting results of (hydroxy)chloroquine in clinical trials are closely related to their drug profile and minor lysosomotropism, but not to the mode of action (lysosomotropism) in general. Observations in patients treated with chlorpromazine and the extensive accumulation of imipramine in alveolar macrophages and of both, imipramine and chlorpromazine in isolated perfused lung tissue supports the benefits of lysosomotropic drugs that are accumulating in pulmonary tissue in SARS-CoV-2 infection/ COVID-19.

Promising candidates among lysosomotropic drugs in fact require more than adequate lysosomotropism; accumulation in pulmonary tissue is a prerequisite as well. It is, however, likely irrelevant whether the drug or its metabolite(s) is accumulating given the broad structural requirements for this activity. Since a large number of compounds has not yet been evaluated for lysosomotropism, many compounds beside those listed in Figure 1A are expected to meet the requirements described here and may (partially) be responsible for background immunity to SARS-CoV infection.

\section{REFERENCES}

Beauverd, Y., Adam, Y., Assouline, B., and Samii, K. (2020). COVID-19 infection and treatment with hydroxychloroquine cause severe haemolysis crisis in a patient with glucose-6-phosphate dehydrogenase deficiency. Eur. J. Haematol. 105, 357. doi:10.1111/ejh.13432

Belouzard, S., Millet, J. K., Licitra, B. N., and Whittaker, G. R. (2012). Mechanisms of coronavirus cell entry mediated by the viral spike protein. Viruses 4, 1011-1033. doi:10.3390/v4061011

Blaess, M., Bibak, N., Claus, R. A., Kohl, M., Bonaterra, G. A., Kinscherf, R., et al. (2018). NB 06: from a simple lysosomotropic aSMase inhibitor to tools for elucidating the role of lysosomes in signaling apoptosis and LPS-induced inflammation. Eur. J. Med. Chem. 153, 73-104. doi:10.1016/j.ejmech.2017. 09.021

Chen, T., Wu, D., Chen, H., Yan, W., Yang, D., Chen, G., et al. (2020). Clinical characteristics of 113 deceased patients with coronavirus disease 2019: retrospective study. BMJ 368, m1091. doi:10.1136/bmj.m1091

Chung, H.-Y., Kollmey, A., Schrepper, A., Kohl, M., Bläss, M., Stehr, S., et al. (2017). Adjustment of dysregulated ceramide metabolism in a murine model of sepsis-induced cardiac dysfunction. IJMS 18, 839. doi:10.3390/ijms18040839

COVID-19 Treatment Guidelines Panel (2020). Coronavirus disease 2019 (COVID-19) treatment guidelines. COVID-19 treatment guidelines. Available at: https://www.covid19treatmentguidelines.nih.gov/ (Accessed July 17, 2020).

de Wit, E., Feldmann, F., Cronin, J., Jordan, R., Okumura, A., Thomas, T., et al. (2020). Prophylactic and therapeutic remdesivir (GS-5734) treatment in the rhesus macaque model of MERS-CoV infection. Proc. Natl. Acad. Sci. U.S.A. 117, 6771-6776. doi:10.1073/pnas.1922083117

Delgado-Roche, L., and Mesta, F. (2020). Oxidative stress as key player in severe acute respiratory syndrome coronavirus (SARS-CoV) infection. Arch. Med. Res. 51, 384-387. doi:10.1016/j.arcmed.2020.04.019

Dyall, J., Coleman, C. M., Hart, B. J., Venkataraman, T., Holbrook, M. R., Kindrachuk, J., et al. (2014). Repurposing of clinically developed drugs for treatment of middle east respiratory syndrome coronavirus infection. Antimicrob. Agents Chemother. 58, 4885-4893. doi:10.1128/AAC. 03036-14

Eimer, J., Vesterbacka, J., Svensson, A. K., Stojanovic, B., Wagrell, C., Sönnerborg, A., et al. (2020). Tocilizumab shortens time on mechanical ventilation and

\section{AUTHOR CONTRIBUTIONS}

MB conceived the work. MB, LK, OS, SR, RC, and H-PD wrote the manuscript. All authors have read and agreed to the published version of the manuscript.

\section{FUNDING}

Funding from the Institute of Precision Medicine, the Federal Ministry of Science, Research and Art of Baden-Wuerttemberg, Germany (researchership for LK) and the Institute for Applied Research (IAF, Furtwangen University, Schwenningen, Germany) is gratefully acknowledged.

\section{ACKNOWLEDGMENTS}

We thank Edith Walther for her tremendous technical support in performing elaborate cell experiments and sample preparation in the initial stages of conceptual work, as well as Petra and Peter Bauer, the staff at Riesling Apotheke (Ellerstadt, Germany), and Apotheke im Markt (Heidelberg, Germany) for their tremendous support.

length of hospital stay in patients with severe COVID-19: a retrospective cohort study. J. Intern. Med., 13162. doi:10.1111/joim.13162

Garner, O. B., Aguilar, H. C., Fulcher, J. A., Levroney, E. L., Harrison, R., Wright, L., et al. (2010). Endothelial galectin-1 binds to specific glycans on nipah virus fusion protein and inhibits maturation, mobility, and function to block syncytia formation. PLoS Pathog. 6, e1000993, doi:10.1371/journal.ppat. 1000993

Han, S. J., Kim, H. S., Kim, K. I., Whang, S. M., Hong, K. S., Lee, W. K., et al. (2011). Use of nafamostat mesilate as an anticoagulant during extracorporeal membrane oxygenation. J. Korean Med. Sci. 26, 945. doi:10.3346/jkms.2011. 26.7.945

Harrison, C. (2020). Focus shifts to antibody cocktails for COVID-19 cytokine storm. Nat. Biotechnol. 38, 905-908. doi:10.1038/s41587-020-0634-9

Hoffmann, M., Schroeder, S., Kleine-Weber, H., Müller, M. A., Drosten, C., and Pöhlmann, S. (2020). Nafamostat mesylate blocks activation of SARS-CoV-2: new treatment option for COVID-19. Antimicrob. Agents Chemother. 64, e00754-20. doi:10.1128/AAC.00754-20

Huang, C., Wang, Y., Li, X., Ren, L., Zhao, J., Hu, Y., et al. (2020). Clinical features of patients infected with 2019 novel coronavirus in Wuhan, China. Lancet 395, 497-506. doi:10.1016/S0140-6736(20)30183-5

Ip, A., Berry, D. A., Hansen, E., Goy, A. H., Pecora, A. L., Sinclaire, B. A., et al (2020). Hydroxychloroquine and tocilizumab therapy in COVID-19 patients-an observational study. PLoS One 15, e0237693. doi:10.1371/ journal.pone. 0237693

Kornhuber, J., Tripal, P., Reichel, M., Terfloth, L., Bleich, S., Wiltfang, J., et al. (2008). Identification of new functional inhibitors of acid sphingomyelinase using a structure-property-activity relation model. J. Med. Chem. 51, 219-237. doi:10.1021/jm070524a

Kuipers, M. T., Zwieten, R., Heijmans, J., Rutten, C. E., Heer, K., Kater, A. P., et al. (2020). Glucose-6-phosphate dehydrogenase deficiency-associated hemolysis and methemoglobinemia in a COVID -19 patient treated with chloroquine. Am. J. Hematol. 95. doi:10.1002/ajh.25862

Levi, M., and Thachil, J. (2020). Coronavirus disease 2019 coagulopathy: disseminated intravascular coagulation and thrombotic microangiopathyeither, neither, or both. Semin. Thromb. Hemost. doi:10.1055/s-0040-1712156

Liu, J., Cao, R., Xu, M., Wang, X., Zhang, H., Hu, H., et al. (2020). Hydroxychloroquine, a less toxic derivative of chloroquine, is effective in inhibiting SARS-CoV-2 infection in vitro. Cell Discov. 6, 16. doi:10.1038/ s41421-020-0156-0 
Macintyre, A. C., and Cutler, D. J. (1988). The potential role of lysosomes in tissue distribution of weak bases. Biopharm. Drug Dispos. 9, 513-526. doi:10.1002/ bod. 2510090602

Masters, P. S. (2006). The molecular biology of coronaviruses. Adv. Virus Res. 66, 193-292. doi:10.1016/S0065-3527(06)66005-3

Mehta, P., McAuley, D. F., Brown, M., Sanchez, E., Tattersall, R. S., and Manson, J. J. (2020). COVID-19: consider cytokine storm syndromes and immunosuppression. Lancet 395, 1033-1034. doi:10.1016/S0140-6736(20)30628-0

Midgley, I., Hood, A. J., Proctor, P., Chasseaud, L. F., Irons, S. R., Cheng, K. N., et al. (1994). Metabolic fate of 14C-camostat mesylate in man, rat and dog after intravenous administration. Xenobiotica 24, 79-92. doi:10.3109/00498259409043223

Millet, J. K., and Whittaker, G. R. (2015). Host cell proteases: critical determinants of coronavirus tropism and pathogenesis. Virus Res. 202, 120-134. doi:10.1016/ j.virusres.2014.11.021

Mingo, R. M., Simmons, J. A., Shoemaker, C. J., Nelson, E. A., Schornberg, K. L., D'Souza, R. S., et al. (2015). Ebola virus and severe acute respiratory syndrome coronavirus display late cell entry kinetics: evidence that transport to NPC1+endolysosomes is a rate-defining step. J. Virol. 89, 2931-2943. doi:10. 1128/JVI.03398-14

Mitjà, O., and Clotet, B. (2020). Use of antiviral drugs to reduce COVID-19 transmission. Lancet Glob. Health 8, e639-e640. doi:10.1016/S2214-109X(20)30114-5

Okajima, K., Uchiba, M., and Murakami, K. (1995). Nafamostat mesilate. Cardiovasc. Drug Rev. 13, 51-65. doi:10.1111/j.1527-3466.1995.tb00213.x

Ono Pharmaceuticals (2020). Foipan Camostat Mesilate Oral Tablets (Ono Pharmaceuticals). Available at: http://www.shijiebiaopin.net/upload/product/ 201272318373223.PDF (Accessed May 6, 2020).

Ou, X., Liu, Y., Lei, X., Li, P., Mi, D., Ren, L., et al. (2020). Characterization of spike glycoprotein of SARS-CoV-2 on virus entry and its immune cross-reactivity with SARS-CoV. Nat. Commun. 11, 1620. doi:10.1038/s41467-020-15562-9

Palmer, K., Dick, J., French, W., Floro, L., and Ford, M. (2020). Methemoglobinemia in patient with G6PD deficiency and SARS-CoV-2 infection. Emerg. Infect. Dis. 26, 2279. doi:10.3201/eid2609.202353

Pettit, N. N., Nguyen, C. T., Mutlu, G. M., Wu, D., Kimmig, L., Pitrak, D., et al. (2020). Late onset infectious complications and safety of tocilizumab in the management of COVID-19. J. Med. Virol., 26429. doi:10.1002/jmv.26429

Tang, N., Ong, W.-Y., Zhang, E.-M., Chen, P., and Yeo, J.-F. (2007). Differential effects of ceramide species on exocytosis in rat PC12 cells. Exp. Brain Res. 183, 241-247. doi:10.1007/s00221-007-1036-7

Thomas, R. L., Matsko, C. M., Lotze, M. T., and Amoscato, A. A. (1999). Mass spectrometric identification of increased $\mathrm{C} 16$ ceramide levels during apoptosis. J. Biol. Chem. 274, 30580-30588. doi:10.1074/jbc.274.43.30580
Varga, Z., Flammer, A. J., Steiger, P., Haberecker, M., Andermatt, R., Zinkernagel A. S., et al. (2020). Endothelial cell infection and endotheliitis in COVID-19. Lancet 395, 1417-1418. doi:10.1016/S0140-6736(20)30937-5

Vincent, M. J., Bergeron, E., Benjannet, S., Erickson, B. R., Rollin, P. E., Ksiazek, T. G., et al. (2005). Chloroquine is a potent inhibitor of SARS coronavirus infection and spread. Virol. J. 2, 69. doi:10.1186/1743-422X-2-69

Wang, Y., Zhang, D., Du, G., Du, R., Zhao, J., Jin, Y., et al. (2020). Remdesivir in adults with severe COVID-19: a randomised, double-blind, placebocontrolled, multicentre trial. Lancet 395, 1569-1578. doi:10.1016/S01406736(20)31022-9

Weston, S., Coleman, C. M., Haupt, R., Logue, J., Matthews, K., and Frieman, M. B. (2020). Broad anti-coronaviral activity of FDA approved drugs against SARSCoV-2 in vitro and SARS-CoV in vivo. J. Virol. 94 (21), e01218-e01220. doi:10. 1101/2020.03.25.008482

Wilson, A. G., Sar, M., and Stumpf, W. E. (1982). Autoradiographic study of imipramine localization in the isolated perfused rabbit lung. Drug Metab. Dispos. 10, 281-283.

Yoshimoto, F. K. (2020). The proteins of severe acute respiratory syndrome coronavirus-2 (SARS CoV-2 or n-COV19), the cause of COVID-19. Protein J. 39 (3), 198-216. doi:10.1007/s10930-020-09901-4

Zhou, D., Dai, S.-M., and Tong, Q. (2020). COVID-19: a recommendation to examine the effect of hydroxychloroquine in preventing infection and progression. J. Antimicrob. Chemother. 75, 1667-1670. doi:10.1093/jac/dkaa114

Zhou, N., Pan, T., Zhang, J., Li, Q., Zhang, X., Bai, C., et al. (2016). Glycopeptide antibiotics potently inhibit cathepsin $\mathrm{L}$ in the late endosome/lysosome and block the entry of ebola virus, middle east respiratory syndrome coronavirus (MERS-CoV), and severe acute respiratory syndrome coronavirus (SARS-CoV). J. Biol. Chem. 291, 9218-9232. doi:10.1074/jbc.M116.716100

Conflict of Interest: The authors declare that the research was conducted in the absence of any commercial or financial relationships that could be construed as a potential conflict of interest.

Copyright (c) 2020 Blaess, Kaiser, Sommerfeld, Rentschler, Csuk and Deigner.. This is an open-access article distributed under the terms of the Creative Commons Attribution License (CC BY). The use, distribution or reproduction in other forums is permitted, provided the original author(s) and the copyright owner(s) are credited and that the original publication in this journal is cited, in accordance with accepted academic practice. No use, distribution or reproduction is permitted which does not comply with these terms. 